\title{
The role of Self-efficacy, Positive Affect and Social Support on Drug Residents' Resilience
}

\author{
Mulia Sari Dewi ${ }^{1}$, Trya Dara Ruidahasi ${ }^{2}$ \\ \{mulia.sari@uinjkt.ac.id ${ }^{1}$ \} \\ Faculty of Psychology, UIN Syarif Hidayatullah Jakarta
}

\begin{abstract}
Undergoing a rehabilitation program is a long process for drug residents, therefore resilience is needed to complete the program. This study aims to determine the effect of self-efficacy, positive affect, and social support on the resilience of drug residents. There were 221 drug residents at rehabilitation institutions in Bogor and Jakarta who participated in this research. They completed Connor-Davison Resilience Scale (CD-RISC) developed by Connor and Davidson [5], Generalized Self-efficacy Scale (GSE) developed by Schwarzer and Jerusalem [30], Positive and Negative Affect Schedule (PANAS) developed by Watson, Clark, \& Tellegen [7], and The Social Provision Scale developed by Cutrona and Russell [28]. Confirmatory Factor Analysis was used to test the construct validity of measuremnets, and multiple regression analysis techniques to test the model. The results indicate that there was a significant effect of self-efficacy, positive affect, and social support on the resilience of drug residents $(\mathrm{R} 2=.58)$. This finding suggest rehabilitation institution to maintain positive affect, develop self-efficacy and confidence among residents to enhance their resilience during rehabilition program. The result also revelad that guidance is the significant type of social support that influence resilience
\end{abstract}

Keywords: Self-efficacy; positive affect; social support; resilience; resident of drug abuse rehabilitation

\section{Introduction}

Resilience is a factor that enables a person to produce, encourage, and even become stronger through difficult circumstances. For a resident of drug abuse rehabilitation, having good resilience is a very important thing to be able to complete all rehabilitation processes. Rehabilitation is a long and not easy process for drug residents. In that long process, some of the problems that often arise in rehabilitation were residents who fled, until the suicide attempt because they could not stand the rehabilitation process.

There are two psychological factors associated with resilience, risk factors and protective factors [1], Risk factors are factors that increase the likelihood of maladaptation, while protective factors are factors with characteristics that can improve adaptability. Protective factors include life satisfaction, optimism, positive affect, selfefficacy, self-esteem, and social support. The purpose of this research is to investigate the effect of self-efficacy, positive affect, and social support on the resilience in resident of drug abuse rehabilitation. 


\section{Theoretical Background}

\subsection{Resilience}

Resilience is one of personal characteristics that discribe individuals ability to overcome change or misfortune successfully [2], to stand firm and adapt in difficult circumstances [3][4], expressed resilience as the quality of a person's ability to survive, adjust to difficult conditions, and be able to continue life after experiencing unpleasant things or situations with heavy pressure.

According to Connor dan Davidson [5], resilience involved 5 compenent (1) Personal competence, high standards and tenacity that supports someone to feel as someone who is able to achieve goals in situations of setbacks or failures, (2) believe in self, have a tolerance for negative effects and strong in dealing with stress that related to calmness in the face of stress, (3) accept changes positively and can make a safe relationship with others that related to adaptability while facing changes, (4) control or self-control in achieving goals and how to ask for or get help from others, and (5) spiritual influence, belief in God and destiny.

Self-efficacy is one of the internal factors that affect resilience, because it affects someone has confidence in their ability to organize tasks to achieve a certain goal, it will help each individual to be able to use well in every difficult problem. The results of the Sagone and Caroli [6] study showed results that showed a positive effect of selfefficacy on resilience. Other internal factors that also influence resilience are positive influences. Positive Affect (PA) reflects some people who are passionate, active, and alert. High PA is a state of high energy, full concentration, and pleasant relationships with other individuals, while low PA is characterized by sadness and lethargy [7].

Based on previous research, Smith et. Al. [8] state that it is the relationship between positive influence and resilience. Zautra et. A1. [9], produce findings that produce individuals with a high positive influence, characterizing individuals with high resilience. In addition to internal factors that affect a person, there are also external factors, namely social support. The results of the research by Hee Lee et. al [10] states that one of the external factors that support important resilience is social support. The results of Schultz et. Al. [11] state positive social support with a degree of resilience. In the results of his research also explained the types of higher social support

\subsection{Self-efficacy}

According to Bandura, the theory of self-efficacy enforces that all forms of processes of psychological and behavioral change through changes in an individual's perception of selfmastery are called self-efficacy [12]. Self-efficacy is initially defined as a type of expectation that is almost specific and is related to an individual's belief in his ability to perform certain behaviors or sets of behaviors needed to achieve a certain outcome [13]. The definition of selfefficacy is certainly expanded, but still refers to the definition that self-efficacy is an individual's belief in his ability to control events that affect his life [14]. Bandura [15] also states that self-efficacy is an individual's belief in his ability to mobilize motivation, cognitive resources, and actions needed to control task demands. Thus, selfefficacy refers to "not an assessment of the skills an individual has, but an assessment of what an individual can do with the skills he has" [16]. 


\subsection{Positive affect}

The dominant two dimensions consistently appear in studies of affective structures, both in the United States and in a number of other cultures. This dimension appears as the first two factors in the analysis of factors about mood with self-rated and as the first two dimensions in the multidimensional scale of the mood [17][18]. Watson and Tellegen [19] have summarized relevant evidence and presented a model of two basic consensual factors called positive affect and negative affect and have been used more broadly in the mood literature with self-report. The terms positive affect and negative affect may indicate that these two mood factors are opposite (highly correlated).

Positive and negative affect actually appears as a very distinctive dimension that can be described meaningfully as a different dimension in the analysis of influence factors. Mood is a condition that has positive affect and negative affect [20][21]. Positive Affect (PA) reflects the extent to which a person feels enthusiastic, active, and alert. High PA is a state of high energy, full concentration, and pleasant relationships with other individuals, while low PA is characterized by sadness and lethargy. Conversely, Negative Affect (NA) is a general dimension of subjective stress and unpleasant involvement that covers a variety of unpleasant moods, including anger, humiliation, disgust, guilt, fear, and nervousness, with low NA being a calm state [22].

\subsection{Social support}

Social support according to Sarafino \& Smith [23] is a comfort, concern, appreciation, or assistance obtained by individuals from other individuals or groups. According to Reitschlin, et. al. [24], social support can come from parents, spouses or lovers, siblings, social or community contacts or even from loyal pets. Sarason, et. al. [25] states that social support is the presence of a number of people who can be relied on by individuals when the individual needs help and there is a degree of satisfaction with the support received. According to Cutrona [26] social support can be defined and applied in many forms, which can be felt as a protective source against things that are detrimental to both physical and psychological health. Social support is the provision of information that will make a person feel himself cared for, loved, respected, and valued [27]. 
There are six dimensions of social support according to Weiss [28], including: (1). Attachment This type of social support is where there is a feeling of closeness that is emotionally attached to other individuals who provide a sense of security for those who receive it. Individuals who receive this type of social support feel calm, safe, and peaceful which is shown by being calm and happy. The most frequent and common source of this type of social support is obtained from spouses, close friends, or family members. (2). Social integration (social integration) In this type of social support allows one to get a feeling of belonging to a group. Where there is the same feeling of interest, concern and recreational activities. Usually obtained from friends and this type of support can provide comfort, security, satisfaction and identity. (3). Reassurance of worth (recognition) In this type of social support a person is recognized for his expertise. Where individuals also get awards from other people or an institution. Sources of this type of social support can come from families, schools or organizations and institutions or agencies. (4). Reliable alliance (dependability to be reliable) In this type of social support individuals feel confident that there are other people who can be relied on to help adjust problems that are visible. Fulfillment of this aspect of support can be sourced from family members or peers. (5). Guidance (guidance) This type of support is in the form of work relations or social relations. Where in the relationship allows individuals to get information, advice and advice needed to meet needs and overcome the problems at hand. This type of support can be sourced from teachers, mentors, elder figures, or parents. (6). Opportunity for nurturance (opportunity to feel needed) This type of support is in the form of a feeling that other people depend on themselves to get their welfare. Fulfillment of this aspect is usually obtained from children and couples. Although in this need a person provides social support and instead receives social support, providing social support to others is also associated with better health. In addition, giving and getting help also goes through the same mechanism of cognition.

\section{Methods}

Participants in this study were drug residents who were attending a rehabilitation program in the Jakarta and Bogor areas, namely the KARISMA Foundation, BNN Lido Bogor, RSKO Jakarta, and the Azalea Recovery Foundation.

\subsection{Participants}

The sample in this study amounted to 221 people, where the amount was adjusted to the needs of the study as well as the time, energy and research funding. The characteristics of the sample in this study were addicts or victims of drug abuse who were undergoing a program in a rehabilitation center, which was called a drug resident.

\subsection{Data collection}


The Drug Resident who participated in filling out the questionnaire in this study was a resident at the primary stage. The stage where residents begin to socialize and join structured communities that have hierarchies, daily schedules, group therapy, individual counseling, and group counseling as supporting media for self-change. Data collection in this study uses a questionnaire filled in classically. The sampling method in this study was nonprobability sampling by convenience sampling technique. To measure the resilience of the measuring instrument used is The Connor-Davidson Resilience Scale (CD-RISC) by Connor and Davidson [29], which contains 25 items. The scale model of this gauge is likert scale 1 to 5 (Disagree, Less Agree, Agree Agree, Agree, Strongly Agree) and based on 5 aspects of resilience according to Connor \& Davidson, namely personal competence, trust in yourself, accept change positively self-control, and spiritual influence (in Singh \& Yu, 2010). Then to measure self-efficacy in this study will use the GSE (Generated Self-efficacy Scale) designed by Schwarzer and Jerusalem [30]. GSE comes from Germany and has been adapted to different cultures. This scale consists of 10 items with likert models on a scale of 1 to 4 . This gauge has an alpha reliability index ranging from 0.75 to 0.90 . Then the positive affect variable uses the Positive and Negative Affect Schedule (HOT) measure developed by Watson, Clark, \& Tellegen [31]. This measurement scale consists of 20 items selfreport measure that affect positive and negative (10 items per construct). This measuring instrument is used because based on the theory by Watson, Clark, \& Tellegen states that positive affect and negative affect are two different dimensions, so that in this study using this measure to measure positive affect. This measurement scale has a satisfactory alfacronbach coefficient ranging from 0.86 to 0.90 .

To measure social support in this study, we will use the measurement scale of The Social Provision Scale [32] based on the six components that form social support, namely: Attachment, Social Integration, Reassurance of Worth, Reliable Alliance, Guidance, and Opportunity for Nurturance. This scale consists of 24 items with a Likert model scale 1 to 4 . All the measuring instruments are tested for validity with CFA by using 3 criteria for valid items, namely: the factor load cannot be negative, t-value $>1.96$ or $>-1.96$ and the number of correlations Maximum error between items 3.

\subsection{Data analysis}

This study uses multiple regression analysis consisting of $1 \mathrm{DV}$ and $8 \mathrm{IV}$. Resilience becomes a dependent variable. Self-efficacy, positive affect, and social support as independent variables. The dimensions of social support (attachment, social integration, reassurance of worth, reliable alliance, guidance, and opportunity for nurturance).

\section{Results}

\subsection{Role of Self-efficacy, Positive Affect and Social Support on Resilience}

To find out the percentage $(\%)$ of the dependent variable variance explained by the independent variable using $\mathrm{R}$ square analysis.

Table 1. R Square 


\begin{tabular}{ccccc}
\hline Model & R & R Square & Adjusted R Square & Std. Error of the Estimate \\
\hline 1 & $.767^{\text {a }}$ & .589 & .573 & 6.26176 \\
\hline
\end{tabular}

a. Predictors: (Constant), self-efficacy, positive affect, attachment, social integration, reassurance of worth, reliable alliance, guidance, opportunity for nurturance

In table 1. it can be seen that R Square is 0.589 or $58.9 \%$. That is, the variance proportion of resilience explained by self-efficacy, positive affect, attachment, social integration, reassurance of worth, reliable alliance, guidance, and opportunity for nurturance is $58.9 \%$, while the remaining $41.1 \%$ is influenced by other variables outside of research this. To test whether all independents have a significant effect on resilience. The F test results can be seen in table 2. below:

Table 2. Anova

\begin{tabular}{cccccc}
\hline Model & Sum of Squares & df & Mean Square & F & Sig. \\
\hline 1 Regression & 11891.470 & 8 & 1486.434 & 37.910 & $.000^{\mathrm{b}}$ \\
Residual & 8312.439 & 212 & 39.210 & & \\
Total & 20203.909 & 220 & & & \\
\hline
\end{tabular}

a. Predictors: (Constant), self-efficacy, positive affect, attachment, social integration, reassurance of worth, reliable alliance, guidance, opportunity for nurturance b. Dependent Variable: R

Based on the $F$ test in table 2. it can be seen that the value of $p$ (Sig.) In the far right column is $p=0.000$ with a value of $p<0.05$. So, thus the null hypothesiswhich reads "there is no effect of self-efficacy, positive affect, and social support (attachment, social integration, reassurance of worth, reliable alliance) for resilience" is rejected. That is, there is a significant positive influence on self-efficacy, positive affect, and social support (attachment, social integration, reassurance, reliability, guidance, opportunity for nurturance) to resilience.

The next step, the authors look at the regression coefficients of each IV. If $\operatorname{sig}<0.05$, the regression coefficient is significant, which means that the independent variable has a significant effect on resilience. The magnitude of the regression coefficient of each independent variable on resilience can be seen in table 3.

Table 3.

\begin{tabular}{lccccc}
\hline & B & Std. Error & Beta & & \\
\hline 1 (Constant) & -4.581 & 192 & & -.882 & .379 \\
Self-Efficacy & 581 & 56 & .494 & 9.272 & $.000^{*}$ \\
Positive Affect & .193 & 52 & .184 & 3.716 & $.000^{*}$ \\
Attachment & .041 & 67 & .035 & .609 & .543 \\
Social Integration & -.041 & 57 & -.042 & -.719 & .473 \\
Reassurance of Worth & .098 & 51 & .102 & 1.931 & .055 \\
Reliable Alliance & .041 & 72 & .036 & .574 & .567 \\
Guidance & .228 & 70 & .191 & 3.249 & $.001^{*}$ \\
Opportunity for Nurturance & .317 & 033 & .015 & .307 &
\end{tabular}


Based on table 3, the significance of each independent variable is seen from the Sig. Sig value. $<0.05$ indicates that the resulting regression coefficient is significant. The results obtained show 3 significant regression coefficients, namely selfefficacy, positive affect, and guidance. While the other 5 variables are attachment, social integration, reassurance of worth, reliable alliance, and opportunity for nurturance do not show a significant regression coefficient.

\subsection{Role of self-efficacy on resilience}

Obtained a regression coefficient of .581 with a significance level of .000 ( $\mathrm{sig}<0.05)$. Thus, the null hypothesis which says there is no effect of selfefficacy on resilience is rejected. This means that the variable self-efficacy has a significant effect on resilience. The direction of the positive coefficient explains that the higher the variable self-efficacy, the higher the resilience.

\subsection{Role of positive affect on resilience}

Obtained a regression coefficient of .193 with a significance level of .000 (sig 0.05). Thus the null hypothesis that reads no effect of attachment on resilience is accepted. This means that the attachment variable has no significant effect on resilience.

\subsection{Role of social support on resilience}

Obtained a regression coefficient of -.041 with a significance level of .473 (sig > 0.05). Thus the null hypothesis which says no influence of social integration on resilience is accepted. This means that the social integration variable has no negative effect on resilience.

Obtained a regression coefficient of .098 with a significance level of .055 ( $\mathrm{sig}>0.05)$. Thus the null hypothesis that reads no effect of reassurance of worth on resilience is accepted. This means that the variable reassurance of worth has no significant positive effect on resilience.

Variable reliable alliance Obtained a regression coefficient of .041 with a significance level of .567 ( $\mathrm{sig}>0.05)$. Thus the null hypothesis that sounds there is no effect of reliable alliance on acceptable resilience. This means that the reliable alliance variable has no significant positive effect on resilience.

Variable guidance Obtained a regression coefficient of .228 with a significance level of .001 (sig 0.05). Thus the null hypothesis which says there is no influence of opportunity for nurturance on resilience is accepted. This means that the opportunity for nurturance variable has no significant positive effect on resilience. 


\section{Discussion}

The focus of this research is to find out the factors that can influence the resilience of drug residents. Based on the data obtained shows $\mathrm{R}$ square of 0.589 or $58.9 \%$. This means that the variables selfefficacy, positive affect, and social support influence the change in variable resilience by $58.9 \%$. Thus the change in the resilience variable amounting to the remaining $41.1 \%$ can be explained by variables other than self-efficacy, positive affect, and social support.

Self-efficacy has a significant influence on the resilience of drug residents who are in the process of rehabilitation. The level of individual confidence in his ability to control events in an individual's life affects resilience. This is consistent with the discussion in previous studies [33] stating that resilience arises or grows from self-confidence in an individual's ability to control events in his life, ability to overcome changes, and problem solving skills. An individual's confidence in his ability to control events in his life depends on his personality and skills in problem solving in the individual.

In this study, the authors saw confidence in the ability of respondents to be obtained from various activities held by rehabilitation centers. Activities held by rehabilitation sites such as individual counseling or group counseling, so that from these activities the respondents get motivation in themselves to believe in their abilities. Then religious activities, where respondents get spiritual enlightenment so that they can increase motivation in the respondent to believe in their ability to control events in their lives.

Positive affect also has a significant influence on resilience of drug residents who are following the rehabilitation process. Affection that reflects the extent to which someone feels enthusiastic, active, and alert influences resilience. This is consistent with the results of a previous study by Smith et. al. [34] states that there is a positive relationship between positive affect and resilience. In addition, Zautra et. al. [35], also produces consistent findings that individuals with positive affect are high, characterizing individuals who are more resilient in facing difficult conditions. A sense of enthusiasm, active and alert for the respondents in the study was also obtained from the rehabilitation center, where residents were indeed nurtured to be more independent and accountable to themselves.

Every active, enthusiastic and alert resident will be assessed by someone who is called a major in rehabilitation, if the resident shows enthusiasm, is active and is aware of the rewards obtained. This increases resident motivation in building enthusiasm, active and alert during the rehabilitation process. In addition, positive affections on respondents also grew out of activities in rehabilitation that were carried out regularly, discipline, and together. As among them there are morning meetings and function activities carried out every day by the residents. In this study there is a dimension of social support that affects resilience, which is positive. Guidance or guidance is one form of support that allows individuals to get information, advice, or advice needed to meet needs and overcome problems faced. That this type of support comes from teachers, mentors, or parents. Respondents in this study, namely residents received good guidance in the rehabilitation center. Guidance at the place of rehabilitation has been given since the first day the resident joined the rehabilitation program. This support is sourced from major and / or counselors who are in charge of rehabilitation. Based on previous research, shows that social support has a positive effect on resilience [36]. 
In this study, attachments did not have a significant effect on resilience. Attachment or attachment in question is where individuals get emotional closeness so as to create a sense of security for the individual. Social integration is the feeling of having interest, and the same activity also does not have a significant effect on resilience. Reassurance of worth is the recognition of the environment that an individual is a valuable person and has the ability to do something that also does not have a significant effect on resilience. Reliable alliance, namely the belief that there are other people who can be relied on to help adjust problems also have no significant effect on resilience. Opportunity for nurturance, namely the feeling that other people depend on themselves to get welfare does not have a significant effect on resilience.

The source of support above does not have a significant effect on resilience, usually obtained from a partner, friend, or family. The author sees residents as respondents lacking in attachment to other residents, this can be due to the duration of residents in different rehabilitation so that it creates less mutual trust in other residents because residents are fairly new to each other in rehabilitation.

The strength of this study is to use drug resident respondents with a considerable scope, namely drug residents in several institutions in the Jakarta and Bogor areas. The limitation in conducting this research is in dealing with residents, because there are some residents who did not fill out the questionnaire properly. It needs good ability to communicate with the resident in order to provide the information needed, as well as the accuracy to check the questionnaire that has been filled by the resident to be sure to have filled all the information needed.

\section{Conclusion}

Based on the results of the research data analysis, the conclusions that can be drawn from this research are that there is a significant positive influence together from self-efficacy, positive affect, and social support to the resilience of drug residents. Then based on the results of a minor hypothesis test that tests the significance of each regression coefficient on the dependent variable, three variables are obtained with significant positive influences namely (1) self-efficacy, (2) positive affect, and (3) social support. In the social support variable, there is only one dimension that has a significant influence, namely guidance, and the other five dimensions do not significantly affect resilience, namely attachment, social integration, reassurance of worth, reliable alliance, and opportunity for nurturance.

\section{References}

[1] Ballenger-Browning, K., Johnson, D. C. Key Facts on Resilience. Naval Center for Combat \& Operational Stress Control. (2010).

[2] Wagnild, G., \& Young, H. Development and psychometricevaluation of the Resilience Scale. Journal of Nursing Measurement. (1993).

[3] Reivich, K., \& Shatte, AThe resilience factor. New York: Random House, Inc. . (2002).

[4] Tugade, M., M. and Fredrickson, B., L. Resilient individuals use positive emotions to bounce back from negative emotional experiences. Journal of Personal and Social Psychology, 86, 320-333. (2004).

[5] Connor, K. M., \& Davidson, J. R. T. Development of a new resilience scale: the connordavidson resilience scale (CD-RISC). Wiley-Liss, Inc Research Acticle. (2003).

[6] Sagone, E., \& Caroli, M. E. D. Relationship between resilience, self-efficacy, and thinking styles in Italian middle adolescents. Journal of Social and Behavioral Science. (2013). 
[7] Watson, D., Clark, L. A., \& Tellegen, A. Development andvalidation of brief measures of positive and negative affect: ThePANAS scales. Journal of Personality and Social Psychology, 54, 1063-1070. (1988).

[8] Smith, B. W., Dalen, J., Wiggins, K., Tooley, E., Christopher, P., \& Bernard, J. The Brief Resilience Scale: Assessing the ability to bounce back. International Journal of Behavioral Medicine. (2008).

[9] Zautra, A. J., Johnson, L. M., \& Davis, M. C. Positiveaffect as a source for resilience for women in chronicpain. Journal of Consulting and Clinical Psychology, 73, 212-220. (2005).

[10] Lee, J. H., Nam, S. K., Kim, A. R., Kim, B., Lee M. Y., \& Lee, S. M. Resilience: a metaanalytic approach. Journal of Counseling and Development, 91, 269-279. (2012).

[11] Schultz, P., Roditti, M., Gillette, M. Resilience, Social Support, and Psychological Disturbance in Hispanic Women Residing in a Battered Women's Shelter on the U.S./Mexico Border. New York: Springer. (2009).

[12] Maddux, J. E. Self-efficacy, Adaptation, and Adjustmen: Theory, Research, and Application. New York: Plenum Press. (1995).

[13] Bandura, A., Nancy, E. A. Analysis f self-efficacy theory of behavioral of behavioral change. Cognitive Therapy and Research. (1977).

[14] Bandura, A. Human agency in social cognitive theory. American Psychologist, 44, 1175- 1184. (1989).

[15] Maddux, J. E. Self-efficacy, Adaptation, and Adjustmen: Theory, Research, and Application. New York: Plenum Press. (1995).

[16] Bandura, A. Social foundations of thought and action: A social cognitive theory. Englewood Cliffs, NJ: Prentice-Hall. (1986).

[17] Watson, D., Clark, L. A., \& Tellegen, A. Development andvalidation of brief measures of positive and negative affect: ThePANAS scales. Journal of Personality and Social Psychology, 54, 1063-1070. (1988).

[18] Zevon, M., A. \& Tellegen, A. The structure of mood changes: an idiographic/nomotethic analysis.Journal of Personality and Social Psychology. (1982).

[19] Watson, D., Clark, L. A., \& Tellegen, A. Development andvalidation of brief measures of positive and negative affect: ThePANAS scales. Journal of Personality and Social Psychology, 54, 1063-1070. (1988).

[20] 16 Zevon, M., A. \& Tellegen, A. The structure of mood changes: an idiographic/nomotethic analysis.Journal of Personality and Social Psychology. (1982).

[21] Watson, D., Clark, L. A., \& Tellegen, A. Development andvalidation of brief measures of positive and negative affect: ThePANAS scales. Journal of Personality and Social Psychology, 54, 1063-1070. (1988).

[22] Watson, D., Clark, L. A., \& Tellegen, A. Development andvalidation of brief measures of positive and negative affect: ThePANAS scales. Journal of Personality and Social Psychology, 54, 1063-1070. (1988).

[23] Sarafino, E. P. \& Smith, T. W. Health psychology: biopsychosocial interaction. United States: John Wiley \& Sons, Inc. (2011).

[24] Taylor, S. E. Health Psychology: 9th Ed. New York: McGraw Hill. (2015).

[25] Ogden, J. Health psychology textbook third edition. Berkshire: Mc Graw Hill Pers. (2004).

[26] Cutrona, C. E., \& Russel, D. W. The Provisions of social relationships and adaptation to stress. In Jones W. H. \& Perlman D. (EDS), Advances in Personal Relationships. Greenwich CT: JAI Press Inc. (1987).

[27] Cohen, S., \& Hoberman, H. Positive events and social supports as buffers of life change stress. Journal of Applied Social Psychology. (1983).

[28] Cutrona, C. E., \& Russel, D. W. The Provisions of social relationships and adaptation to stress. In Jones W. H. \& Perlman D. (EDS), Advances in Personal Relationships. Greenwich CT: JAI Press Inc. (1987). 
[29] Connor, K. M., \& Davidson, J. R. T. Development of a new resilience scale: the connordavidson resilience scale (CD-RISC). Wiley-Liss, Inc Research Acticle. (2003).

[30] Schwarzer, R., \& Jerusalem, M. Generalized SelfEfficacy scale. In J. Weinman, S. Wright, \& M. Johnston, Measures in health psychology: A user's portfolio. Causal and control beliefs (pp. 35-37). Windsor, UK: NFERNELSON. (1995).

[31] Watson, D., Clark, L. A., \& Tellegen, A. Development andvalidation of brief measures of positive and negative affect: ThePANAS scales. Journal of Personality and Social Psychology, 54, 1063-1070. (1988).

[32] Cutrona, C. E., \& Russel, D. W. The Provisions of social relationships and adaptation to stress. In Jones W. H. \& Perlman D. (EDS), Advances in Personal Relationships. Greenwich CT: JAI Press Inc. (1987).

[34] Tusaie, K., \& Dyer, J. Resilience: A historical review of theconstruct. Holistic Nursing Practice, 18, 3-10. (2004).

[34] Smith, B. W., Dalen, J., Wiggins, K., Tooley, E., Christopher, P., \& Bernard, J. The Brief Resilience Scale: Assessing the ability to bounce back. International Journal of Behavioral Medicine. (2008).

[35] Zautra, A. J., Johnson, L. M., \& Davis, M. C. Positiveaffect as a source for resilience for women in chronicpain. Journal of Consulting and Clinical Psychology, 73, 212-220. (2005).

[36] Schultz, P., Roditti, M., Gillette, M. Resilience, Social Support, and Psychological Disturbance in Hispanic Women Residing in a Battered Women's Shelter on the U.S./Mexico Border. New York: Springer. (2009). 